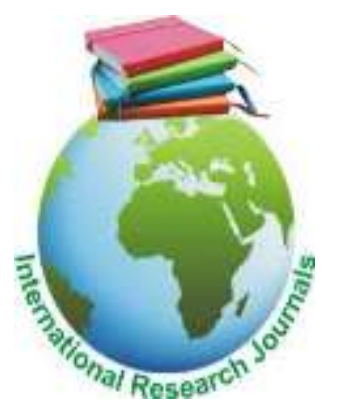

Journal of Research in International Business and Management (ISSN: 2251-0028) Vol. 5(1) pp. 90-95, August 2018

Available online http://www.interesjournals.org/JRIBM

DOI: http:/dx.doi.org/10.14303/jribm.2018.019

Copyright @ 2018 International Research Journals

Review Article

\title{
Cultural gyroscope model: Matching staff with organizations
}

\author{
${ }^{1 *}$ Weiku W and ${ }^{2}$ Jiayin Z \\ ${ }^{1}$ Department of Leadership and Organization Management, School of Economics and Management, \\ Tsinghua University, Beijing, China. ${ }^{2}$ Department of Leadership and Organization Management, School of \\ Economics and Management, Tsinghua University, Beijing, China. \\ *Corresponding Author's Email: wuwk@sem.tsinghua.edu.cn
}

\section{Abstract}

The classical model of corporate culture is that of a static pie model composed of four levels: the conceptual level, the institutional level, the behavioral level, and the artifact level. Based on the theory of gyrodynamics, this paper advances the cultural gyroscope model for the purpose of matching staff and organizations. The cultural gyroscope model defines the conceptual level of culture as the axis of the gyroscope; the institutional, behavioral, and artifact levels as the flywheel of the gyroscope; staff as a particle on the flywheel; and entrepreneurship as the driving force for the rotation of the gyroscope. This model, which features both simplicity and inclusiveness, dynamically integrates culture, entrepreneurship, the match between staff and culture and interprets corporate culture from a comprehensive perspective.

Keywords: Corporate culture model, the match between staff and organization, cultural gyroscope, Leadership.

\section{INTRODUCTION}

One's mind guides one's behaviors. The behaviors of a few people create an atmosphere; the behaviors of many people develop a culture, and multiple cultures form history. Culture refers to the way we do things and serves as the standard for us to tell right from wrong as well as to judge the order of priorities (Drucker 2011; Robinson and Judge 2014; Shein 2010). At present, static conceptual maps, such as the four-level pie model (Figure 1), are used to describe corporate culture (Shein 2010). Culture, however, is constantly in flux. The reform of organizational culture is driven by entrepreneurs' leadership and requires staff to adapt to the organizational culture (Blake 1985). This study aims to provide a culturally dynamic model that 
incorporates entrepreneurs' driving force for culture and employees' adaptability to organizational norms and values, in a comprehensive manner.

\section{Static Models of Corporate Culture and Their Limitations}

A large range of culture models has been advanced. The most classic variant is the four-level pie model (Shein 2010). Therein, culture is divided into four levels in terms of internal and external structural elements: the conceptual, institutional, behavioral, and artifact levels, as shown in Figure 1. As the core of corporate culture, the conceptual level consists of a variety of factors including the corporate spirit, business style, corporate mission, cultural statements, social responsibilities, and employees' beliefs. Concepts offer a set of norms to converge toward unity in thinking. Requiring others to think in a certain way is a soft constraint and serves as the mental identity of the corporate identity system (CIS). The institutional and behavioral levels offer a set of norms to guarantee unity in behaviors. Requiring others to act in a certain way is a hard constraint and serves as the behavior identity of the CIS. The artifact level is the physical evidence and serves as the visual identity of the CIS. Together these constitute the corporate culture system as well as the employees' identity system. To determine whether an employee belongs to an organization is to decide whether he/she matches the organization's culture at all of these levels.

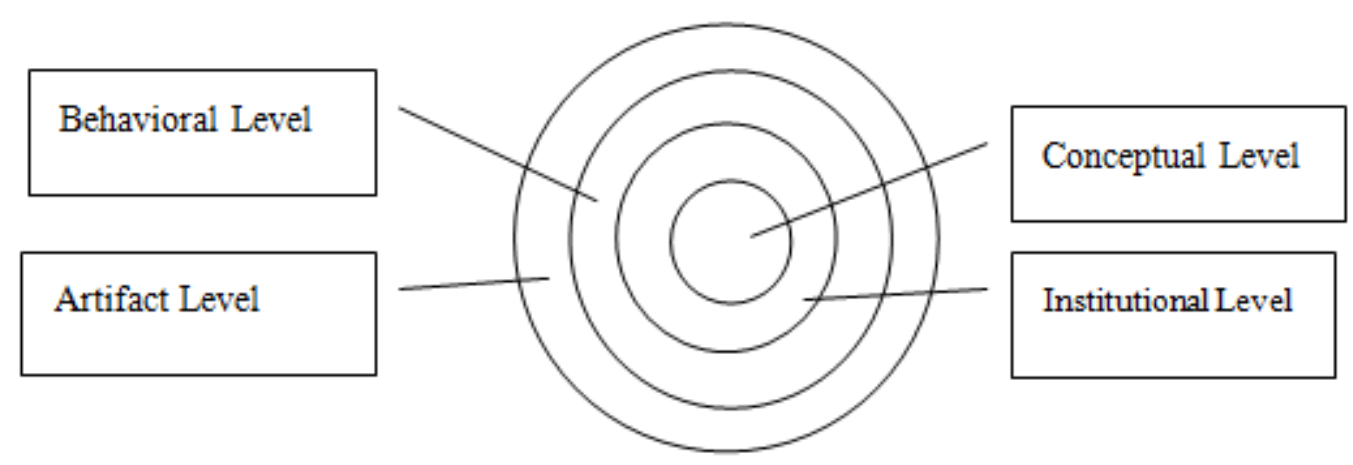

Figure 1: Four-level conceptual pie model of corporate culture.

According to the constitution of corporate culture, concepts are at the core and impose constraints on thoughts, understanding, and attitudes. We can comprehend the conceptual system as corporate values, which would facilitate deeper communication and interpretation among organizational actors. Thus, we define corporate values as the corporate conceptual system, which refers to the norms to restrain one's mindset, the requirements on ways of thinking, the way to determine the order of priorities, and how to tell right from wrong. The corporation is a platform where people who share the same values get together and realize their values. A leader's job is, by virtue of clear values, to unite people in recognition of shared values to achieve common objectives. This is so called value-based leadership (Wu 1999, 2016). This concept requires corporate leaders to have clear values and keep their values up-to-date. An employee needs to find an organization to match his/her values and constantly adjust his/her values to keep up with 
contemporary phenomena and ensure a dynamic match with the values of the organization. This cannot be described in full by static pie models.

For this reason, a dynamic culture model is needed to depict the dynamics of values and the dynamic match between the values of the employees and the organization.

\section{The Dynamic Model of Corporate Culture}

A gyroscope will come into being if we stretch the conceptual level in the static four-level pie model to be an axis, and locate the behavioral, institutional, and artifact levels in terms of the flywheel. Since a gyroscope must keep rotating to stand up steadily, there must be a force to drive the rotation. Torque is the force in mechanics, but in corporate culture, it is entrepreneurship. This is the gyroscope model of corporate culture, as shown in Figure 2.

\section{Matching Staff and Corporate Culture}

Employees may develop three types of relationships with the corporation: adapting themselves to the corporation, changing the corporation to work for themselves, or resigning from the corporation, that is, either being changed by your boss, changing your boss, or leaving your boss. In the game between staff and corporate entities, staff members should be able to clearly understand their chips. They need to figure out the answer to one question: "At the current stage, do I need the corporate more, or it's the other way round?" Given that individuals are usually at a disadvantage in the game with the organization, they need to adapt themselves to the organization in most cases. To survive in the organization, staff members should fit into the organization's culture (Robinson and Judge 2014; Shein 2010; Davies et al. 1998).

In the framework of the gyroscope model, staff could be compared to a particle on the gyroscope, like the small ball in Figure 2. The particle in the rotating gyroscope would generate the centrifugal force F1, a force directed away from the axis of rotation. To prevent being thrown out of the scope, the particle must produce the centripetal force F2 to defy the centrifugal force (Tang and Wang 2013; Wang 2013; Xue et al. 2018). To produce $\mathrm{F} 2$, the particle must adhere to the gyroscope and such adhesive force is called identification, that is, a sense of belonging arising from identifying with the organization. Different degrees of identification produce different magnitudes of adhesive force. A high degree of identification would produce enough F2 to offset $\mathrm{F} 1$ and thus resist the particle's movement in a sideways direction. A low degree of identification means weak adhesive force that would result in insufficient F2 to defy $F 1$, and the particle will move sideways. When the particle moves to the edge of the flywheel, it means that the individual has been marginalized. When F1 is great enough, the particle will be thrown out of the flywheel, which means the separation of the individual from the organization.

If the particle is able to take the initiative to move toward the gyroscope's axis, this represents the employee moving closer to the core of the organization. When the particle converges at the axis, it means the employee has become a part of the organization's core and a mainstay to support the implementation of the organization's culture.

In a rotating gyroscope, all particles would produce $\mathrm{F} 1$ and have a feeling of being thrown out. It means that, especially in a large organization, all staff members except for the top leader would feel marginalized, 
and feel behind the organizational changes to some extent (Kotter 2008). It is normal to have such feelings, which are in fact illusions. Do not be deluded by such illusions that can lead you to be marginalized in reality. You need to motivate yourself to actively move toward the axis and enhance your identification with the organization's culture to keep up with organizational changes.

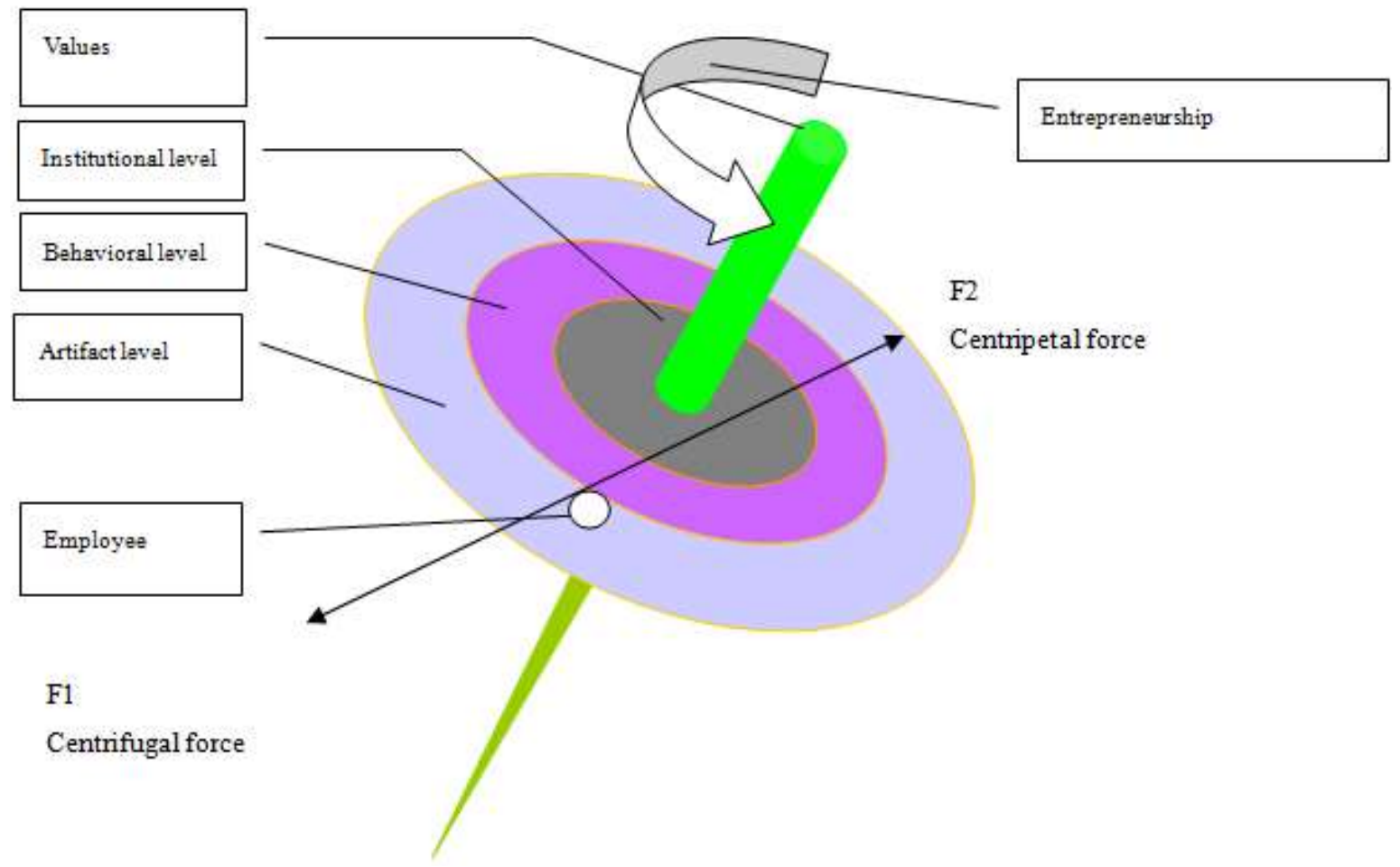

Figure 2: The Cultural Gyroscope Model: Matching Staff and Corporate Culture.

If a staff member could adapt to the evolutionary dynamics of the corporate culture, he/she will feel just like a fish in water. If a staff member cannot keep up with the organizational culture, it is because he/she cannot fit into the corporate culture and, thus, fails to embrace it completely, just like a particle with weak adherence to the gyroscope that finally gets marginalized due to lack of centripetal force.

\section{Features of the Cultural Gyroscope Model}

The cultural gyroscope model boasts appropriate explanations of corporate culture, based on the following: 1. The cultural gyroscope model upgrades the two-dimensional depiction of corporate culture into threedimensions. It is simple and inclusive to describe the constitution of corporate culture through the gyroscope model.

2. The cultural gyroscope model changes the static depiction of corporate culture to a dynamic depiction. The metaphor of the gyroscope's rotation is used to describe the changing nature of corporate culture and the dynamic adaptability between culture and environment. Since the corporation's internal and external environments are constantly changing, corporate culture must be able to dynamically adapt to the environment. The gyroscope will fall down if it stops rotating. To stand up, it must keep spinning and then it can adapt to whatever environment it is placed in. The same is true with the corporation. If the corporate 
culture is as dynamically adaptable to the environment as the gyroscope is, the corporation will be able to adapt to environmental changes, advance with the times and remain viable. This indicates that outstanding corporate culture constitutes the core competitiveness of a corporation.

3. The cultural gyroscope model takes the human resource factor (Robinson and Judge 2014) into consideration. In the process of adapting corporate culture to dynamic environments, staff members need to enhance their identification with the corporate culture to survive and actively move toward the axis to enter the core and become the mainstay of the cultural gyroscope.

4. The cultural gyroscope model brings entrepreneurship into the cultural model. There must be a force to spin the gyroscope, and the force is exerted by entrepreneurship that is activated by corporate leaders and implemented by the entire staff (Danereau 1995; Li and Zhang 2006; Wang et al. 2006). Entrepreneurs are the driving force in building corporate culture. In line with the corporate values, corporate leaders help to shape the staff to fit cultural requirements. As the Chinese saying goes, if you are not members of the same family, you will not be able to enter through that family's door. For example, Lenovo welcomes new employees with its New-hire Orientation Program ("into the mold" training in Chinese), which helps to mold new employees into staff alike to senior employees in various respects so that they can survive in the company. First, to become a Lenovo person and, then, to grow to be a Lenovo leader (Zhang 2015).

5. The gyroscope model sheds light on the inertia generated by enterprises. The rotation speed of the gyroscope and the size of the flywheel represent the inertia of the organization. A high rotation speed multiplied by a large flywheel mass produces greater inertia, which means that the corporation's cultural inertia is greater (Tang and Wang 2013; Wang 2013; Xue et al. 2018). Increasing inertia in corporate culture requires painful efforts for construction and reforms. The larger the gyroscope's mass, the greater is the inertia; thus, more power is required for the rotation (Tang and Wang 2013; Wang 2013; Xue et al. 2018). The mass of the gyroscope represents the size of a corporation. It is easier for a small boat to turn round compared to a large ship because the former is less burdened by inertia. It requires sizeable efforts to build culture in a large corporation and even more to change the culture. The culture of a small corporation could be changed by the leaders, but institutions are needed for cultural change in larger entities.

6. The cultural gyroscope model highlights the core function of values. Values are the axis of the gyroscope and support other components in corporate culture. The axis must be placed at the center of the flywheel, which demonstrates that the construction of organizational culture must be centered on values. Here values are the key link. Only when the key link is grasped will everything fall into place. Both the system of rewards, penalties, and promotions and the system of artifacts (or physical evidence) must be based on values, so that the employee's mindset and behavior do not go awry. Corporate activities should be resultoriented but must stay on the path of corporate values. Just like that the goal of a train is to reach the destination, but if the train gets derailed, it will never reach the destination. With airplanes being on course, boats in smooth waterways, trains on track, and pedestrians on zebra crossing, tomorrow will be better.

Any problems in a corporation could be traced back to problems with values. Values are invisible and, thus, belong to Nothingness. Behavior is visible and, thus, belongs to Existence. Existence is decided by Nothingness, as the ancient Chinese philosopher Lao Tzu said, "All things of the world are born from Existence (Being); and Being from Nothingness." It would be insightful and wise for corporate leaders to grasp Nothingness and create Existence from Nothingness, just as it is said in The Governing Principles of Ancient China, "Insightful people can anticipate troubles ahead of time. Wise people can anticipate danger 
before danger takes shape."

A Story

To study how one's values could be affected by the mother during childhood, a scholar interviewed three men who each shared a story about their mothers' distribution of apples. The first story goes like this: When he was a kid, his mom bought a few apples one day and each of them wanted the biggest one. Mom said, "Whoever finish mowing the lawn first will get the big apple." He finished mowing first and got the biggest apple. Since then he learned that one's gains are proportional to the efforts he/she made. He grew up to be a successful man working at the White House. Here is the second story: When he was a kid, his mom bought some apples one day. His little brother asked for the biggest one, but mother told his brother that "a good kid gives away better things to others." Hearing this, he asked for a small one. Mom said, "The one who asks for small apple deserves a big one." He got the biggest apple. Since then he learned to lie. He grew up to be a prisoner. The third story goes like this: When he was a kid, his mom bought a few apples one day and they all wanted the biggest one. Mom told them to go to work and whoever finishes chopping the firewood first will get the biggest one. When he came back after chopping the firewood, he saw his little brother eating the big apple in his mother's arms. He complained, "Didn't you say that whoever finishes the work gets the big apple?" Mom said, "You're the eldest kid. You should take good care of your little brothers." He walked away helplessly. He grew up to be an ordinary man.

This indicates that the incentive system should be in line with the values and that manifested values should be consistent with implicit values; otherwise the staff would be at a loss. This may lead to double standards and is equivalent to having two different leadership systems; policies from the two systems may confuse the staff about which one to follow. All policies should be centered on values and the institution's mission should be to safeguard those values. People will make efforts as advocated by the policies and finally foster the values consistent with the institution. Just like a Chinese saying goes: as you sow, so shall you reap. Where the institution fails to cover, values shall play a role.

\section{CONCLUSION}

There are various models of corporate culture but almost all of them are static. These models only describe the content of a given culture, failing to incorporate other factors such as the initiators of cultural reform, executors of culture, and roles that people play therein. Based on the four-level cultural model, this study advances a simple and concise cultural gyroscope model to explain the match between employees and organization. A gyroscope is composed of an axis and a flywheel. Corporate values are compared to the axis, while the metaphor of the flywheel is used for the institutional, behavioral, and artifact levels. Entrepreneurship is the driving force for the gyroscope's rotation. The employee is compared to a particle on the flywheel, and the employee's identification with the corporate culture is compared to the particle's adherence to the flywheel. Particles on a rotating gyroscope generate centrifugal force F1, while particles' adherence to the flywheel produces centripetal force F2. When the centrifugal force F1 equals the centripetal force F2, the particle stays on the flywheel. When F1 is larger than F2, the particle will move sideways and be marginalized, even if it is separated from the gyroscope. However, if the particle could actively move toward the axis, it may arrive at the center and enter the core of the gyroscope. 
Once the gyroscope begins spinning, it rotates automatically by virtue of inertia, but to keep it spinning sustainably, extra force is needed and that force is entrepreneurship. As corporate culture advances with time, all employees except for the top leader will have a feeling of being marginalized which is, in fact, a normal illusion. One needs to take the initiative to move closer to the core and finally grow to be part of the mainstay of the corporation.

\section{REFERENCES}

1. Robert RB, Jame SM (1985). Managerial Grid III, Houston: Gulf.

2. Fred D. (1995). A Dyadic Approach to Leadership: Creating and Nurturing This Approach Under Fire, Leadership Quarterly 6: 479-490.

3. Michaela D, Stankov L, Roberts RD (1998). Emotional intelligence: In search of an elusive construct. Journal of Personality and Social Psychology, 75: 989-1015.

4. Peter DF (2011). The Practice of Management. London and New York: Routledge.

5. Kotter, John P 2008. Power and Influence. New York: Free Press.

6. Huajing L, Zhang Y (2006). Entrepreneurial Leaders: The New Role of firms' Top Management Team. Soft Science.

7. Stephen P, Judge TA (2014) Organizational Behavior (16 ${ }^{\text {th }}$ Edition). London: Pearson.

8. Edgar HS (2010). Organizational Culture and Leadership (4 ${ }^{\text {th }}$ Edition). San Francisco: JosseyBass.

9. Nan T, Jiamei W (2013). University Physics ( $2^{\text {th }}$ Edition). Beijing: Higher education publisher.

10. Chongming W, Yang Z (2006). The Theory and Research Trends of Entrepreneurial Leadership, Psychological Science.

11. Wei W (2013). Review on Inertial Technology. Acta Automatica Sinica.

12. Lian LX, Chun CS, Zhen CX (2018). A Review of Inertial Technology Development. Navigation and Control.

13. Weiku W (2016). Value-Based Leadership. Beijing: Mechanical engineering publisher

14. Weiku W (1999). The Application of Value-Based Leadership in China Knowledge-Based Enterprises. Journal of Tsinghua University (Philosophy and Social Sciences).

15. Tao Z (2015). Ask Liu: The Three Factors of Liu Chanzhi's Management. Hangzhou: Zhejiang People's Publishing House. 